\title{
PENGARUH ANTENATAL PERINEAL MASSAGE PADA PRIMIGRAVIDA TERHADAP PROSES PERSALINAN DI KOTA SEMARANG TAHUN 2017
}

\author{
THE EFFECT OF ANTENATAL PERINEAL MASSAGE ON PRIMIGRAVIDA TO THE \\ PROCESS AT LABOR IN SEMARANG CITY 2017
}

\author{
Erna Kusumawati ${ }^{1}$ Agustin Rahmawati ${ }^{2}$ Siti Istiana $^{3}$ \\ 1,2,3 Program Studi DIII Kebidanan Fakultas Ilmu Keperawatan dan Kesehatan/ Program \\ Studi DIII Kebidanan, Universitas Muhammadiyah Semarang \\ E-mail : ernakusumawati@unimus.ac.id
}

\begin{abstract}
ABSTRAK
Trauma jalan lahir berhubungan erat dengan proses persalinan. Hal ini juga berhubungan dengan angka kesakitan dan kematian Ibu. Proses persalinan hampir 90\% yang mengalami robekan perineum, baik dengan atau tanpa episiotomi. Antenatal Prineal Massage yang dilakukan pada periode kehamilan $\geq 34$ minggu dapat mengurangi terjadinya insiden yang terjadi pada proses persalinan. Tujuan dilakukan penelitian ini adalah melihat efektifitas pemberian antenatal perineal massage terhadap proses persalinan. Metode yang dipakai dalam pencapaian tujuan tersebut menggunakan uji komparatif atau perbedaan dengan dua kelompok sampel yang berbeda yaitu ibu hamil yang diberikan perlakuan perineal massage sebanyak 45 orang dan kelompok kontrol adalah ibu hamil yang tidak diberikan perlakuan apapun sebanyak 45 orang. Hasil penelitian ada perbedaan bermakna antara antara insident episiotomi antara kelompok perlakuan dan kelompok kontrol, tidak ada perbedaan bermakna antara lama Kala II (periode pengeluaran kepala bayi) antara kelompok perlakuan dan kelompok kontrol, ada perbedaan bermakna antara skala nyeri persalinan pada kelompok perlakuan dan kelompok kontrol, tidak ada perbedaan bermakna antara jenis persalinan dengan tindakan pada kelompok perlakuan dan kelompok kontrol.
\end{abstract}

Kata Kunci : Proses Persalinan, Antenatal Perineal Massage, Primigravida

\section{ABSTRACT}

Trauma of the birth canal is closely related to labor. It is also related to the morbidity and mortality rate of the mother. The birth process is almost $90 \%$ of those with perineal rupture, either with or without an episiotomy. Antenatal Prenatal Massage performed at the gestation period of $\geq 34$ weeks can reduce the incidence occurring in labor or postpartum. The purpose of this study was to see the effectiveness of antenatal perineal massage on the process at labor. The method used in achieving these goals using comparative or difference test with two different sample groups of pregnant women given perineal massage treatment of 45 people and the control group is pregnant women who are not given any treatment as much as 45 people. The results of the study there were significant difference between the incidence of episiotomy between treatment group and control group, no significant difference between the duration of Kala II (infant head release period) between treatment group and control group, there were significant difference between the scale of labor pain in treatment group and control group, no significant difference between the type of labor action in treatment group and control group at the end of measurement.

Keywords: Perineal Laseration, Antenatal Perineal Massage, Primigravida 


\section{PENDAHULUAN}

Setiap tahun lebih dari 600.000 wanita meninggal akibat komplikasi pada periode kehamilan dan persalinan. Mayoritas hal tersebut terjadi di beberapa negara berkembang termasuk Indonesia. Perawatan antenatal, perinatal dan postnatal merupakan pelayanan pencegahan dasar untuk melindungi dan meningkatkan kesehatan ibu dan janin sampai tiba saat persalinannya. (Sonmez: 2007).

Jumlah kasus kematian di Kota Semarang hingga bulan Maret 2016 adalah 13 kematian ibu. Waktu kematian ibu terjadi pada masa bersalin $8,57 \%$; hamil $17,14 \%$ dan nifas 74,29\%. Penyebab kematian yaitu perdarahan $28 \%$, Eklamsia $34 \%$, Penyakit $26 \%$ dan lain-lain termasuk infeksi 12\%. Lokasi penyumbang AKI terbanyak di Semarang antara lain di Wilayah Semarang Utara (bandarhardjo), dan Pedurungan. (Dinas Kesehatan Kota Semarang, 2016).

Penyebab kematian ibu perdarahan dan infeksi bisa dikarenakan terjadinya laserasi perineum pada proses persalinan. Sebagian besar wanita mengalami perlukaan jalan lahir akibat proses persalinan spontan, tekhnik episiotomi atau keduanya. Insiden perlukaan/laserasi jalan lahir kurang lebih $85 \%$ dari total persalinan pervaginam. Perlukaan jalan lahir sangat berhubungan erat dengan nyeri pasca persalinan. Faktor resiko yang berhubungan dengan perlukaan jalan lahir yang biasanya terjadi di perineum adalah jenis persalinan dan paritas. (Debra, 2012)

Studi yang dilakukan oleh Beckman and Garret (2006), menemukan pemijatan perineum selama kehamilan dapat menurunkan angka kejadian perlukaan jalan lahir / perineum. Penelitian yang dilakukan oleh Abdul (2015), bahwa tindakan pemijatan perineum dapat menurunkan angka episiotomi / tindakan pelebaran jalan lahir dengan melukai perineum secara sengaja dan meringankan derajad laserasi perineum.

\section{METODE PENELITIAN}

Jenis penelitian adalah kuasi eksperimental dengan pre test-post test control group design. Dalam penelitian ini digunakan dua kelompok, kelompok perlakuan (A) dan kelompok kontrol (B). Model yang digunakan dalam penelitian ini adalah seluruh ibu hamil di Wilayah Semarang Utara dan Pedurungan yang diberikan perlakukan antenatal massage perineum dengan kriteria pengambilan sampel sebagai berikut: Ibu hamil Trimester III (usia kehamilan $\geq 28$ minggu), Primigravida atau wanita yang baru pertama kali hamil, Wanita yang belum memiliki riwayat persalinan pervaginam, Masih berdomisili di Wilayah Semarang Utara, Pedurungan, Bersedia ikut dalam prosedur penelitian dari awal sampai akhir. Kelompok perlakuan dan kontrol dalam penelitian ini berjumlah 45 orang. Analisis univariat menerangkan angka atau nilai jumlah masing- masing variabel dengan ukuran prosentase. Analisa bivariat dilakukan dengan uji hipotesis komparatif (Uji Beda). Dilakukan untuk menguji perbedaan hasil pengamatan antara kelompok perlakuan dan kelompok kontrol.

HASIL DAN PEMBAHASAN

\section{A. Insident Episiotomi Saat Persalinan \\ Tabel 1. Insident Episiotomi Saat Persalinan Kelompok Perlakukan dan Kontrol}

\begin{tabular}{lcccc}
\hline & \multicolumn{2}{c}{ Perlakuan } & \multicolumn{2}{c}{ Kontrol } \\
\cline { 2 - 5 } & $\mathrm{F}$ & $\%$ & $\mathrm{f}$ & $\%$ \\
\hline $\begin{array}{l}\text { Tidak } \\
\text { dilakukan }\end{array}$ & 40 & 88,9 & 32 & 71,1 \\
$\begin{array}{l}\text { episiotomy } \\
\text { Dilakukan } \\
\text { episiotomy }\end{array}$ & 5 & 11,1 & 13 & 28,9 \\
Total & 45 & 100 & 45 & 100 \\
\hline
\end{tabular}

Berdasarkan hasil tabel 1 . pada kelompok perlakukan sebanyak 40 responden $(88,9 \%)$ tidak dilakukan tindakan episiotomi pada 
saat proses persalinan dan sebanyak 5 responden $(11,1 \%)$ dilakukan episiotomi saat persalinan. Pada kelompok kontrol sebanyak 32 responden $(71,1 \%)$ tidak dilakukan tindakan episiotomi dan sebanyak 13 responden $(28,9 \%)$ dilakukan episiotomi saat persalinan.

\section{Tabel 2. Perbedaan Insident Episiotomi pada Kelompok Perlakuan dan Kontrol}

\begin{tabular}{llccc}
\hline & \multicolumn{4}{c}{ Ranks } \\
\cline { 2 - 5 } & $\begin{array}{l}\text { Kelo } \\
\text { mpok }\end{array}$ & $\begin{array}{c}\mathrm{N} \\
\text { Mea } \\
\text { nank } \\
\text { Rand }\end{array}$ & $\begin{array}{c}\text { Sum } \\
\text { of } \\
\text { Ranks }\end{array}$ \\
\hline $\begin{array}{l}\text { Tindak } \\
\text { an } \\
\text { episiot } \\
\text { omi }\end{array}$ & Perlak & 4 & 41,5 & 1867,5 \\
& ukan & 5 & 0 & 0 \\
& & & & \\
& Kontr & 4 & 49,5 & 2227,5 \\
& ol & 5 & 0 & 0 \\
\hline & Total & 9 & & \\
& & 0 & & \\
\hline
\end{tabular}

\begin{tabular}{lr}
\multicolumn{2}{c}{ Test Statistic $^{\mathrm{a}}$} \\
\hline & \multicolumn{1}{c}{$\begin{array}{c}\text { Tindakan } \\
\text { episiotomi }\end{array}$} \\
\hline Mann-Whitney U & 832,500 \\
Wilcoxon W & 1867,500 \\
Z & -2.096 \\
$\begin{array}{l}\text { Asymp. Sig. (2- } \\
\text { tailed) }\end{array}$ & .036 \\
\hline
\end{tabular}

a. Grouping Variable: Kelompok

Hasil uji Mann Whitney, diperoleh nilai $\mathrm{p}=0,036(\mathrm{p}<0,05)$, dapat disimpulkan bahwa "ada perbedaan bermakna antara insident episiotomi antara kelompok perlakuan dan kelompok kontrol pada akhir pengukuran.

Menurut Sarwono (2007), episiotomi merupakan suatu tindakan insisi pada perineum yang menyebabkan terpotongnya selaput lendir vagina, cincin selaput dara, jaringan pada septum rektovaginal, otot-otot dan fasia perineum dan kulit sebelah depan perineum.

Hasil penelitian ini sesuai dengan penelitian oleh Kalichman (2008), dimana perineal massage di kehamilan trimester akhir dapat mengurangi trauma perineum khususnya tindakan episiotomi. Hasil penelitian serupa juga dilakukan oleh Beckman (2006), dimana wanita yang melakukan pijat perineum 16\% lebih sedikit dilakukan episiotomi dan sangat signifikan pada wanita yang baru pertama kali melahirkan.

\section{B. Lama Kala II Persalinan (Periode Pengeluaran Kepala Bayi)}

\begin{tabular}{lcccc}
$\begin{array}{l}\text { Tabel 3. Lama Kala II } \\
\text { (Periode } \\
\text { Bayi) }\end{array}$ & $\begin{array}{c}\text { Persalinan } \\
\text { Pengeluaran }\end{array}$ & \multicolumn{2}{c}{ Kepala } \\
& & & & \\
\hline & \multicolumn{2}{c}{ Perlakuan } & \multicolumn{2}{c}{ Kontrol } \\
\cline { 2 - 5 } & $\mathrm{F}$ & $\%$ & $\mathrm{f}$ & $\%$ \\
\hline Lama & 45 & 10 & 45 & 10 \\
kala II & & 0 & & 0 \\
Mean & 32,4 & & 43,7 & \\
Median & 4 & & 6 & \\
Minimum & 10 & & 15 & \\
Maximu & 5 & & 5 & \\
m & 25 & & 25 & \\
\hline
\end{tabular}

Berdasarkan tabel 3 Lama Kala II atau periode pengeluaran kepala bayi pada kelompok perlakukan didapatkan hasil rata-rata durasi pengeluaran kepala bayi (Kala II) adalah 32 menit. Pada kelompok kontrol didapatkan hasil rata-rata durasi pengeluaran kepala bayi (Kala II) adalah 45 menit.

Proses ini biasanya berlangsung selama 2 jam pada primi dan 1 jam pada multi (Yeyeh, 2009).

Tabel 4. Perbedaan Lama Kala II pada Kelompok Perlakuan dan Kontrol

\begin{tabular}{llll}
\hline & \multicolumn{3}{c}{ Ranks } \\
\cline { 2 - 3 } Kelo & N Mea & Sum \\
\hline
\end{tabular}




\begin{tabular}{|c|c|c|c|c|}
\hline \multirow{3}{*}{$\begin{array}{l} \\
\text { Lama } \\
\text { Kala II }\end{array}$} & \multicolumn{2}{|l|}{ mpok } & $\begin{array}{c}\mathrm{n} \\
\text { Rank }\end{array}$ & $\begin{array}{c}\text { of } \\
\text { Ranks }\end{array}$ \\
\hline & Perlak & 4 & 42,1 & 1898,5 \\
\hline & ukan & 5 & 9 & 0 \\
\hline & Kontr & 4 & 48,8 & 2196,5 \\
\hline & ol & 5 & 1 & 0 \\
\hline & $\mathrm{T}$ & & & \\
\hline
\end{tabular}

Test Statistic ${ }^{\mathrm{a}}$

\begin{tabular}{lr}
\hline & \multicolumn{1}{c}{$\begin{array}{c}\text { Tindakan } \\
\text { episiotomi }\end{array}$} \\
\hline Mann-Whitney U & 863,500 \\
Wilcoxon W & 1898,500 \\
$Z$ & $-1,266$ \\
Asymp. Sig. (2- & .206 \\
tailed) & \\
\hline a. Grouping Variable: Kelompok
\end{tabular}

Hasil uji Mann Whitney, diperoleh nilai $p=0,206(p>0,05)$, dapat disimpulkan bahwa "tidak ada perbedaan bermakna antara lama Kala II (periode pengeluaran kepala bayi) antara kelompok perlakuan dan kelompok kontrol pada akhir pengukuran.

Hasil penelitian ini sama dengan penelitian yang dilakukan Beckman (2006) dimana tidak ada perbedaan pada lama kala II persalinan antara kelompok yang dilakukan pemijatan perineum dan kelompok yang tidak dilakukan pemijatan perineum.

Faktor yang mempengaruhi lama Kala II antara lain tenaga mengejan ibu, faktor janin (berat bayi lahir), faktor jalan lahir (panggul sempit dan kondisi psikis ibu yang sedang bersalin.

C. Nyeri Persalinan

Tabel 5. Skala Nyeri Persalinan Pada Kelompok Perlakuan dan Kontrol

\begin{tabular}{ccccc}
\hline & \multicolumn{2}{c}{ Perlakuan } & \multicolumn{2}{c}{ Kontrol } \\
\cline { 2 - 5 } & $\mathrm{F}$ & $\%$ & $\mathrm{f}$ & $\%$ \\
\hline Nyeri & 45 & 100 & 45 & 100 \\
\hline
\end{tabular}

\begin{tabular}{lcc}
\hline persalinan & & \\
Mean & 3,76 & 5,13 \\
Median & 4 & 5 \\
Minimum & 0 & 2 \\
Maximum & 7 & 8 \\
\hline
\end{tabular}

Berdasarkan tabel 5 skala nyeri persalinan pada kelompok perlakukan didapatkan rata-rata nyeri yang dirasakan oleh responden pada skala 3-4 dimana interpretasinya adalah nyeri ringan atau sedikit sakit yang dirasakan selama proses persalinan terutama kala I (periode dilatasi servix). Skala nyeri 3 yang nyata terasa namun dapat ditoleransi seperti mendapatkan pukulan dihidung . Pada kelompok kontrol didapatkan rata-rata nyeri yang dirasakan oleh responden pada skala 5 dimana interpretasinya adalah nyeri sedang atau sedikit mengganggu dan menyusahkan selama proses persalinan terutama kala I (periode dilatasi servix). Skala nyeri 5 merupakan nyeri kuat dalam dan menusuk seperti terkilir.

Tabel 6. Perbedaan Skala Nyeri Persalinan pada Kelompok Perlakuan dan Kontrol

\begin{tabular}{|c|c|c|c|c|}
\hline & \multicolumn{4}{|c|}{ Ranks } \\
\hline & $\begin{array}{l}\text { Kelo } \\
\text { mpok }\end{array}$ & $\mathrm{N}$ & $\begin{array}{c}\text { Mea } \\
\mathrm{n} \\
\text { Rank }\end{array}$ & $\begin{array}{c}\text { Sum } \\
\text { of } \\
\text { Ranks }\end{array}$ \\
\hline \multirow{8}{*}{$\begin{array}{l}\text { Nyeri } \\
\text { persali } \\
\text { nan }\end{array}$} & Perlak & 4 & 35,1 & 1580,0 \\
\hline & ukan & 5 & 1 & 0 \\
\hline & Kontr & 4 & 55,8 & 2515,0 \\
\hline & & 5 & 9 & 0 \\
\hline & Total & 9 & & \\
\hline & & 0 & & \\
\hline & \multicolumn{4}{|c|}{ Test Statistic ${ }^{a}$} \\
\hline & & \multicolumn{3}{|c|}{$\begin{array}{l}\text { Tindakan } \\
\text { episiotomi }\end{array}$} \\
\hline \multicolumn{3}{|c|}{ Mann-Whitney U } & \multicolumn{2}{|c|}{545,000} \\
\hline \multicolumn{3}{|c|}{ Wilcoxon W } & \multicolumn{2}{|c|}{1580,000} \\
\hline \multicolumn{3}{|l|}{ Z } & \multicolumn{2}{|r|}{$-3,848$} \\
\hline
\end{tabular}


Asymp. Sig. (2-

, 000

tailed)

a. Grouping Variable:Kelompok

Hasil uji Mann Whitney, diperoleh nilai $p=0,000(p<0,05)$, dapat disimpulkan bahwa "ada perbedaan bermakna antara skala nyeri persalinan pada kelompok perlakuan dan kelompok kontrol pada akhir pengukuran.

Hasil penelitian Ajartha (2007), menemukan hanya $15 \%$ persalinan yang berlangsung tanpa nyeri atau nyeri ringan, $35 \%$ persalinan disertai nyeri sedang, 30\% persalinan disertai nyeri hebat dan $20 \%$ persalinan disertai nyeri yang sangat hebat. Penelitian terkait dilakukan oleh Rusdiatin (2007), mendapatkan hasil 53,3\% ibu bersalin mengalami nyeri sedang dan $46,7 \%$ mengalami nyeri persalinan yang berat.

Secara fisiologi nyeri persalinan mulai timbul pada persalinan kala I fase laten dan fase aktif. Fase laten terjadi pembukaan sampai $3 \mathrm{~cm}$, bisa berlangsung selama 8 jam (Rukiyah,2009). Rukiyah (2009) menjelaskan pula bahwa puncak nyeri terjadi pada fase aktif, di mana pembukaan menjadi lengkap sampai $10 \mathrm{~cm}$ dan berlangsung selama 6 jam. Nyeri tersebut berasal dari kontraksi uterus dan dilatasi serviks (Cunningham, 2005). Pada fase aktif kontraksi uterus menjadi lebih lentur, lebih lama, dan lebih kuat sehingga sensasi nyeri yang dirasakan lebih meningkat (Rukiyah,2009).

D. Jenis Persalinan dengan Tindakan Tabel 7. Jenis Persalinan dengan Tindakan Pada Kelompok Perlakuan dan Kontrol

\begin{tabular}{ccccc}
\hline & \multicolumn{2}{c}{ Perlakuan } & \multicolumn{2}{c}{ Kontrol } \\
\cline { 2 - 5 } & F & $\%$ & f & $\%$ \\
\hline Spontan & 39 & 86,7 & 35 & 77,8 \\
\hline
\end{tabular}

\begin{tabular}{lcccc}
\hline Tindakan & 6 & 13,3 & 10 & 22,2 \\
Total & 45 & 100 & 45 & 100 \\
\hline
\end{tabular}

Berdasarkan tabel 7 pada kelompok perlakukan mayoritas bersalin secara spontan sebanyak 39 responden $(86,7 \%)$ dan sebanyak 6 responden $(13,3 \%)$ bersalin dengan tindakan. Pada kelompok kontrol mayoritas bersalin juga secara spontan sebanyak 35 responden $(77,8 \%)$ dan sebanyak 10 responden $(22,2 \%)$ bersalin dengan tindakan.

Tabel 8. Perbedaan Jenis Persalinan dengan Tindakan pada Kelompok Perlakuan dan Kontrol

\begin{tabular}{|c|c|c|c|c|}
\hline & \multicolumn{4}{|c|}{ Ranks } \\
\hline & $\begin{array}{l}\text { Kelo } \\
\text { mpok }\end{array}$ & $\mathrm{N}$ & $\begin{array}{c}\text { Mea } \\
\mathrm{n} \\
\text { Rank }\end{array}$ & $\begin{array}{c}\text { Sum } \\
\text { of } \\
\text { Ranks }\end{array}$ \\
\hline \multirow{8}{*}{$\begin{array}{l}\text { Jenis } \\
\text { tindak } \\
\text { an } \\
\text { persali } \\
\text { nan }\end{array}$} & Perlak & 4 & 43,5 & 1957,5 \\
\hline & ukan & 5 & 0 & 0 \\
\hline & Kontr & 4 & 47,5 & 2137,5 \\
\hline & ol & 5 & 0 & 0 \\
\hline & Total & 9 & & \\
\hline & & 0 & & \\
\hline & \multicolumn{4}{|c|}{ Test Statistic ${ }^{a}$} \\
\hline & & & \multicolumn{2}{|c|}{$\begin{array}{l}\text { Tindakan } \\
\text { episiotomi }\end{array}$} \\
\hline \multicolumn{3}{|c|}{ Mann-Whitney U } & & 922,500 \\
\hline \multicolumn{3}{|c|}{ Wilcoxon W } & & 957,500 \\
\hline \multicolumn{3}{|l|}{$\mathrm{Z}$} & & $-1,097$ \\
\hline \multicolumn{3}{|c|}{$\begin{array}{l}\text { Asymp. Sig. (2- } \\
\text { tailed) }\end{array}$} & & ,273 \\
\hline
\end{tabular}

a. Grouping Variable: Kelompok

Hasil uji Mann Whitney, diperoleh nilai $p=0,273(p>0,05)$, dapat disimpulkan bahwa "tidak ada perbedaan bermakna antara jenis persalinan dengan tindakan pada kelompok perlakuan dan kelompok kontrol pada akhir pengukuran".

Faktor yang mempengaruhi jenis 
persalinan atau komplikasi persalinan sesuai dengan hasil penelitian dari Fauzia (2014) dimana hasil determinan yang berhubungan dengan kejadian komplikasi persalinan adalah paritas, komplikasi kehamilan, penolong persalinan, tempat persalinan, dan pendidikan. Ibu yang memiliki paritas $>5$ anak, mengalami komplikasi kehamilan, bersalin di non kesehatan, berpendidikan rendah memiliki risiko lebih tinggi untuk mengalami komplikasi persalinan.

\section{SIMPULAN}

a. Tindakan episiotomi pada kelompok perlakuan lebih sedikit dibandingkan dengan kelompok kontrol yaitu sebesar $11,1 \%$. Ada perbedaan bermakna antara insident episiotomi antara kelompok perlakuan dan kelompok kontrol pada akhir pengukuran.

b. Lama kala II atau periode pengeluaran kepala bayi pada kelompok perlakuan lebih pendek yaitu 32 menit dibandingkan dengan kelompok kontrol. Tidak ada perbedaan bermakna antara lama Kala II (periode pengeluaran kepala bayi) antara kelompok perlakuan dan kelompok kontrol pada akhir pengukuran.

c. Skala nyeri persalinan pada kelompok perlakuan didapatkan rata-rata nyeri yang dirasakan oleh responden pada skala 3-4 dan pada kelompok kontrol didapatkan rata- rata nyeri yang dirasakan oleh responden pada skala 5. Ada perbedaan bermakna antara skala nyeri persalinan pada kelompok perlakuan dan kelompok kontrol pada akhir pengukuran

d. Pada kelompok perlakukan mayoritas bersalin secara spontan sebanyak 39 responden $(86,7 \%)$ dan pada kelompok kontrol mayoritas bersalin juga secara spontan sebanyak 35 responden $(77,8 \%)$. Ttidak ada perbedaan bermakna antara jenis persalinan dengan tindakan pada kelompok perlakuan dan kelompok kontrol pada akhir pengukuran

\section{DAFTAR PUSTAKA}

Debra, B. (2012). Evidence Based Guidelines for Midwifery-Led Care in Labour. The Royal College of Midwives Trust.

Dinas Kesehatan Kota Semarang. (2016). Porsentase AKI Kota Semarang.

Sonmesz,Y. (2007). The Prenatal Care Service. Turkish, 9-12.

Ajartha. 2007. Efek Pemberian Tramadol Intramuskular Terhadap Nyeri Persalinan pada Primigravida. USU Medan: Tesis, 2007

Beckmann MM, Garret AJ. 2006. Antenatal perineal massage for reducing perineal trauma. The Cochrane database of Systematic Reviews, Isuue 1. Art, No : CD005123.pub2.

Cunningham, F. Obstetric Williams Jilid I. Edisi 21. Jakarta: EGC, 2005.

Fauzia, S. 2014. Faktor - faktor yang Mempengaruhi Komplikasi Persalinan di Indonesia. Jurnal Ilmiah. Depok: FK UI.

Kalichman, L. (2008). Perineal Massage to Prevent Perineal trauma in Childbirth. IMAJ. Vol 10. July 2008.

Rusdiatin, I. 2007. Pengaruh Pemberian Teknik Akupresur Terhadap Tingkat Nyeri Persalinan Kala I di Rumah Sakit Rajawali Citra Pototonobanguntapan Bantul 2007 . Stikes Surya Global Yogyakarta. 
Rukiyah, A. 2009. Asuhan

Kebidanan II (Persalinan).

Jakarta Timur: Trans Info Media. 